\title{
Toward better management of rare and orphan pulmonary diseases
}

\author{
Sergio Harari ${ }^{1}$ and Marc Humbert ${ }^{2}$
}

Affiliations: ${ }^{1}$ Unità Operativa di Pneumologia e Terapia Semi-Intensiva Respiratoria - Servizio di Fisiopatologia Respiratoria ed Emodinamica Polmonare, Ospedale San Giuseppe MultiMedica IRCCS, Milan, Italy. ${ }^{2}$ Centre National de Référence de l'Hypertension Pulmonaire Sévère Hôpital Bicêtre Hôpitaux Universitaires ParisSud, Assistance Publique Hôpitaux de Paris, Le Kremlin-Bicêtre, France.

Correspondence: Correspendence: Sergio Harari, Unità Operativa di Pneumologia e Terapia Semi-Intensiva Respiratoria - Servizio di Fisiopatologia Respiratoria ed Emodinamica Polmonare-Ospedale San Giuseppe MultiMedica IRCCS, Via San Vittore 12, 20123 Milan, Italy. E-mail: sharariahotmail.it

@ERSpublications

Efforts deployed by the ERS and its publications to promote rare disease and orphan drug research http://ow.ly/YNbNN

Following the publication of the last article of the European Respiratory Journal (ERJ)/European Respiratory Review (ERR) series on rare diseases and orphan drugs [1-9], we would like to take the opportunity to highlight that there are several very good reasons for pulmonologists to take rare pulmonary diseases and orphan drugs into due consideration.

Firstly, with a conservative estimate of primary or secondary lung involvement occurring in $\sim 5 \%$ of rare diseases (>6000 types), approximately 1-2 million people in the European Union are likely to be affected by rare pulmonary diseases. Therefore, cumulatively, rare pulmonary diseases account for a significant burden of disease, as many of them are severe conditions that result in premature death or major morbidity [10]. Furthermore, knowledge of rare diseases, or at least learning how to suspect them in a timely fashion, may reduce the usual diagnostic delay that is common to all of them and has very negative impacts on the prognosis of affected patients. A correct diagnosis may in fact be reached with many years of delay, as is the case with lymphangioleiomyomatosis [3], and late diagnosis appears to be an almost insurmountable obstacle. Pulmonary arterial hypertension is a clear example: despite better treatments and major research efforts in the past two decades, no decrease has been registered in the time it takes to attain a final diagnosis after the onset of initial symptoms [11]. Research on rare diseases also represents an exacting testing ground for the development of interdisciplinary professional skills and of international collaborative research networks comprising academic organisations, industrial partners and patient groups. In the case of pulmonary arterial hypertension and, more recently, of idiopathic pulmonary fibrosis, such networking endeavours have led to the implementation of large randomised clinical trials. In addition, a number of drugs first developed as orphan drugs have subsequently been used for different indications. The best known example is that of imatinib mesylate, which was initially developed for chronic myeloid leukaemia and is presently used for other discrete indications in various medical fields.

Many such examples also exist for rare respiratory diseases. Bosentan, a dual endothelin receptor antagonist first registered for the treatment of pulmonary arterial hypertension has subsequently been approved for use in patients with systemic sclerosis to reduce the number of new digital ulcers. Nintedanib, a tyrosine kinase inhibitor recently approved for the treatment of idiopathic pulmonary fibrosis, is now also indicated for the treatment of certain tumours, while some trials are currently investigating other possible indications.

These are only a few of the many reasons why the European Respiratory Society (ERS) promotes and supports guidelines and statements, finances fellowship programmes and many others activities (some in partnership with patients' associations), and coordinates actions against rare pulmonary diseases with European health authorities [10]. With the organisation of courses and dedicated symposia during the ERS

Received: Feb 222016 | Accepted: Feb 222016

Conflict of interest: Disclosures can be found alongside the online version of this article at erj.ersjournals.com

Copyright OERS 2016 
International Congress and with the publication of articles in ERS publications, our Society plays a key role in the process of advancing medical research in this field [10]. Along the same line and following the same philosophy, the ERJ and ERR have recently published two series of review articles discussing hot topics presented at the Sixth International Meeting on Pulmonary Rare Diseases and Orphan Drugs, endorsed by the ERS, which took place in Milan, Italy, on February 27 and 28, 2015. This international conference, held every second year, is entirely dedicated to the management of rare pulmonary parenchymal and vascular diseases and rare variants of more common respiratory conditions (such as severe refractory asthma and emphysema due to $\alpha_{1}$-antitrypsin deficiency) [12-16]. It is the only European event exclusively dedicated to these challenging issues. The conference dates were not chosen randomly, as they coincided with the World Rare Disease Day, first launched in 2008 by EURORDIS (European Organisation for Rare Diseases), a nongovernmental alliance of rare disease patient organisations present in over 50 countries. Rare Disease Day takes place on the last day of February each year, and is held on the 29th, a rare day, in leap years and on the 28th in other years [10]. Proceedings from past annual meetings and several selected reports from the 2011 and 2013 meetings have previously been published in the ERR [17, 18].

The ERR dedicated its September issue last year to selected articles from the Sixth International Meeting on Pulmonary Rare Diseases and Orphan Drugs, and covered varied themes, such as pulmonary hypertension in myeloproliferative disorders [7], interstitial pneumonia in systemic sclerosis [5], real-life studies of idiopathic pulmonary fibrosis [8], smoking-related interstitial lung diseases [6], and pitfalls in methodologies and data interpretation in epidemiological studies of interstitial pulmonary fibrosis [9]. In parallel and in its present issue, the ERJ published a series of authoritative reviews written by international experts in the different topics discussed, such as considerations for future clinical trials in idiopathic pulmonary fibrosis [1], new insights on pathogenesis and possible therapeutic approaches for acute exacerbation of idiopathic pulmonary fibrosis [2], the changing face of very rare diseases such as lymphangioleiomyomatosis [3], and pulmonary veno-occlusive disease [4]. We are confident that the publication of these articles will contribute to advancing our knowledge and raising awareness of rare pulmonary diseases.

Another area that will benefit from greater awareness and attention is that of rare variants of relatively frequent diseases. These conditions can be studied using the same methodological and scientific approach we rely on for rare diseases. The scientific community has made impressive research efforts in a field that was restricted solely to a few scholars until 20 year ago. It is our hope that the efforts and support deployed by the ERS and its publications will help to promote research in the field of rare diseases and orphan drugs.

\section{References}

1 Collard HR, Bradford WZ, Cottin V, et al. A new era in idiopathic pulmonary fibrosis: considerations for future trials. Eur Respir J 2015; 46: 243-249.

2 Ryerson CJ, Cottin V, Brown KK, et al. Acute exacerbation of idiopathic pulmonary fibrosis: shifting the paradigm. Eur Respir J 2015; 46: 512-520.

3 Harari S, Torre O, Cassandro R, et al. The changing face of a rare disease: lymphangioleiomyomatosis. Eur Respir J 2015; 46: 1471-1485.

4 Montani D, Lau EM, Dorfmüller P, et al. Pulmonary veno-occlusive disease. Eur Respir J 2016; 47: 1518-1534.

5 Cappelli S, Bellando Randone S, Camiciottoli S, et al. Interstitial lung disease in systemic sclerosis: where do we stand? Eur Respir Rev 2015; 24: 411-419.

6 Margaritopulos GA, Vasarmidi E, Jacob J, et al. Smoking and interstitial lung disease. Eur Respir Rev 2015; 24: 428-435.

7 Adir Y, Elia D, Harari S. Pulmonary hypertension in patients with chronic myeloproliferative disorders. Eur Respir Rev 2015; 24: 400-410.

8 Harari S, Caminati A. Idiopathic pulmonary fibrosis: from clinical trials to real-life experiences. Eur Respir Rev 2015; 24: 420-427.

9 Caminati A, Madotto F, Cesana G, et al. Epidemiological studies in idiopathic pulmonary fibrosis: pitfalls in methodologies and data interpretations. Eur Respir Rev 2015; 24: 436-444.

10 Harari S, Lau EMT, Tamura Y, et al. Rare (pulmonary) disease day: "feeding the breath, Energy for life!" Eur Respir J 2015; 45: 297-300.

11 O'Callaghan DS, Humbert M. A critical analysis of survival in pulmonary arterial hypertension. Eur Respir Rev 2012; 21: 218-222.

12 Shaw DE, Sousa AR, Fowler SJ, et al. Clinical and inflammatory characteristics of the European U-BIOPRED adult severe asthma cohort. Eur Respir J 2015; 46: 1308-1321.

13 Fleming L, Murray C, Bansal AT, et al. The burden of severe asthma in childhood and adolescence: results from the paediatric U-BIOPRED cohorts. Eur Respir J 2015; 46: 1322-1333.

14 Ortega $\mathrm{H}$, Chupp G, Bardin P, et al. The role of mepolizumab in atopic and nonatopic severe asthma with persistent eosinophilia. Eur Respir J 2014; 44: 239-241.

15 Chung KF, Wenzel SE, Brozek JL, et al. International ERS/ATS guidelines on definition, evaluation and treatment of severe asthma. Eur Respir J 2014; 43: 343-373.

16 Thabut G, Mornex JF, Pison C, et al. Performance of the BODE index in patients with $\alpha 1$-antitrypsin deficiency-related COPD. Eur Respir J 2014; 44: 78-86.

17 Harari S, Cottin V, Humbert M. Global effort against rare and orphan disease. Eur Respir Rev 2012; 21: 171-172.

18 Harari S, Humber M, Cottin V. Future perspective on rare pulmonary diseases and rare presentations of common disorders. Eur Respir Rev 2013; 22: 199-201. 